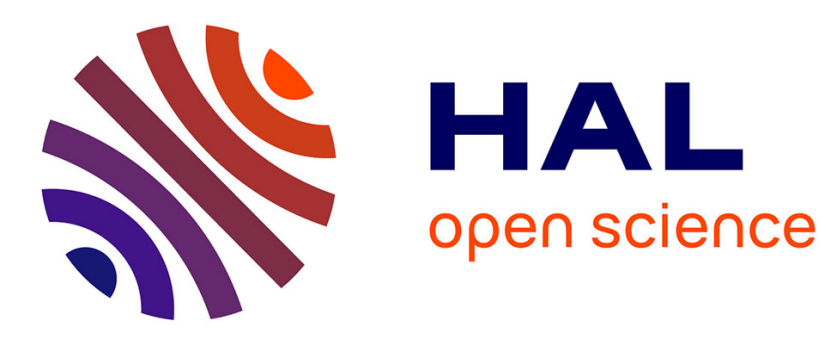

\title{
Characterization of different aggregation stages in implanted LiF crystals
}

\author{
J. Davenas, J. Duppin, Vu Binh, C. Dupuy
}

\section{To cite this version:}

J. Davenas, J. Duppin, Vu Binh, C. Dupuy. Characterization of different aggregation stages in implanted LiF crystals. Journal de Physique Colloques, 1980, 41 (C6), pp.C6-385-C6-389. 10.1051/jphyscol:1980698 . jpa-00220136

\section{HAL Id: jpa-00220136 https://hal.science/jpa-00220136}

Submitted on 1 Jan 1980

HAL is a multi-disciplinary open access archive for the deposit and dissemination of scientific research documents, whether they are published or not. The documents may come from teaching and research institutions in France or abroad, or from public or private research centers.
L'archive ouverte pluridisciplinaire HAL, est destinée au dépôt et à la diffusion de documents scientifiques de niveau recherche, publiés ou non, émanant des établissements d'enseignement et de recherche français ou étrangers, des laboratoires publics ou privés. 


\title{
Characterization of different aggregation stages in implanted LiF crystals
}

\author{
J. Davenas, J. P. Dupin, Vu Thien Binh and C. H. S. Dupuy \\ Département de Physique des Matériaux, 43, bd du 11 Novembre 1918, 69621 Villeurbanne, France
}

\begin{abstract}
Résumé. - Dans des papiers précédents nous indiquions que des ions alcalins implantés dans le fluorure de lithium avaient tendance à former des amas. Nous avons pu montrer par spectroscopie optique la formation d'amas quasi métalliques à température ambiante, ou après des traitements thermiques, tandis que les ions implantés restaient dans un état dispersé à la température de l'azote liquide. La transition de cet état dispersé vers un état granulaire est observée lorsque le cristal est réchauffé à température ambiante.

Des expériences récentes, qui utilisent la rétrodiffusion d'ions lourds Rutherford et la microscopie électronique à balayage indiquent que en corrélation avec cette transition, les ions sont redistribués jusqu'en surface de l'échantillon. Cette nouvelle distribution n'est pas due à des processus de migration des ions implantés, mais à un recul de la surface jusque dans la zone implantée du cristal. Nous donnons une interprétation de cet effet. Nous n'observons pas un tel effet dans des cristaux implantés à température ambiante.
\end{abstract}

\begin{abstract}
In previous papers we reported the tendency of implanted alkali ions to cluster in lithium fluoride crystals. It was possible to show by optical spectroscopy the formation of quasi metallic clusters at room temperature, or after thermal annealings, whereas the implanted ions remained in a dispersed state at liquid nitrogen temperature. The transition from this dispersed state to a granular state is observed when the crystal is warmed up to room temperature.

Recent investigations, using Rutherford backscattering spectroscopy and scanning electron microscopy indicate that in correlation with this transition, implanted ions are redistributed up to the surface of the sample. This new distribution is not due to migration processes of the implanted ions, but to a recoil of the surface to the implanted zone of the crystal. An interpretation of this effect is given. Such an effect is not observed in room temperature implanted crystals.
\end{abstract}

1. Introduction. - In the paper we presented at Berlin [1] we reported the formation of colloidal bands, due to the precipitation of the implanted ions, after thermal annealings. Using Doyle's theory it was possible to show that these bands were due to plasma oscillations of the metallic precipitates [2]. In figure 1 , we give two typical absorption spectra

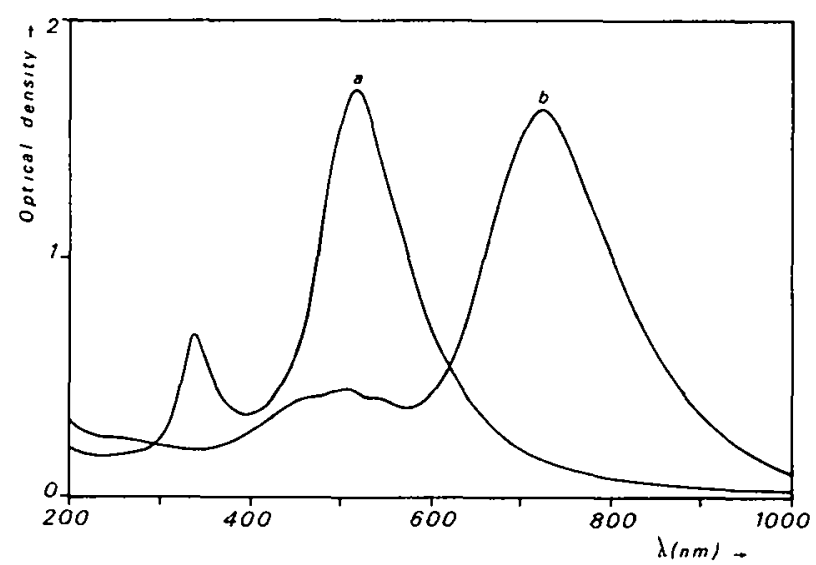

Fig. 1. - Absorption spectra of thermally annealed LiF crystals $\left(1\right.$ hour at $\left.300^{\circ} \mathrm{C}\right):$ a) crystal emplanted with $4.5 \times 10^{16}$ $\mathrm{Na}^{+} / \mathrm{cm}^{2} ; b$ ) crystal implanted with $4.5 \times 10^{16} \mathrm{~K}^{+} / \mathrm{cm}^{2}$. of thermally annealed LiF crystals, that had been implanted with $4.5 \times 10^{16}$ sodium, or potassium, ions per $\mathrm{cm}^{2}$. Figure 2 shows that for ion implanted

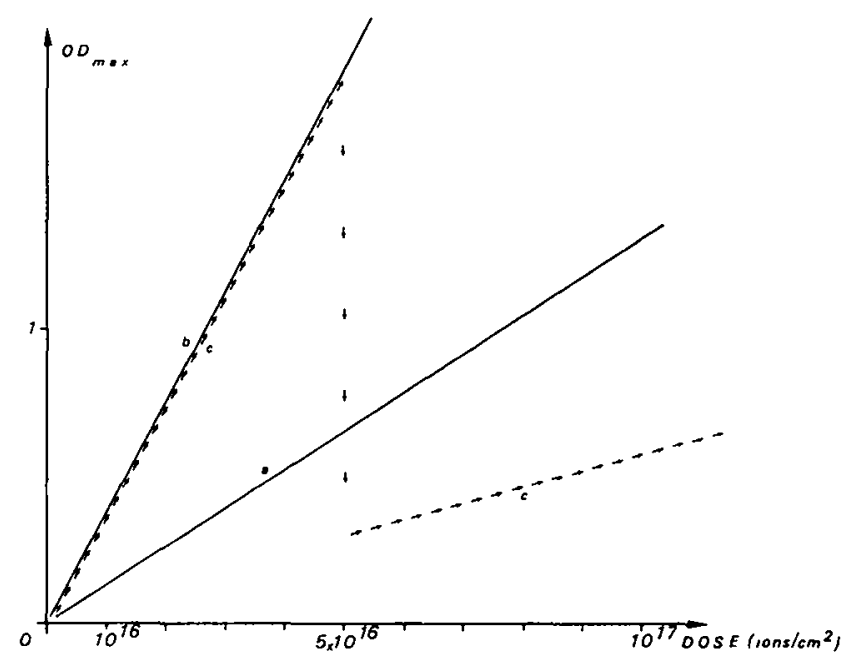

Fig. 2. - Growth curves of the colloidal bands associated to potassium implanted ions versus ion dose : a) absorption band at $620 \mathrm{~nm}$ that appears during implantation at RT; b) colloidal band at $720 \mathrm{~nm}$ obtained after thermal annealings (1 hour at $300^{\circ} \mathrm{C}$ ). RT implanted crystal ; c) colloidal band at $720 \mathrm{~nm}$ obtained after thermal annealings ( 1 hour at $300^{\circ} \mathrm{C}$ ). LNT implanted crystal. 
doses lower than $5 \times 10^{16}$ ions $/ \mathrm{cm}^{2}$ the growth curve of the potassium colloidal band is identical for low temperature (LNT) or room temperature (RT) implanted crystals and is linear with the dose, whereas for higher doses we observe an important drop of the amplitude of the colloidal band of low temperature implanted crystals.

In the paper in reference [1] we also reported the growth of an absorption band, at $620 \mathrm{~mm}$ for potassium, during room temperature implantation that is due to a first stage of precipitation, that goes on after thermal annealings. The growth of this band was blocked at low temperature whereas a wide absorption, attributed to small alkali aggregates of the implanted ions, was observed in the near infrared part of the spectrum. However such a model could not explain all the behaviour of the infrared absorption. In particular it was possible to observe a bleaching effect, after air inlet in the implantation chamber, after the sample had been warmed up to room temperature. This effect was only observed for implanted ion doses higher than a critical dose, that is about $5 \times 10^{16}$ ions $/ \mathrm{cm}^{2}$ for potassium implanted at $500 \mathrm{keV}$. The discoloration is not uniform and a ring shaped colored zone is observed at the limit of the irradiated area of the crystal. The large absorption background of the infrared absorption, which is more important for large wavelengths than for the short ones, suggested us, that a metallic layer ought to be responsible of the anomalous shape of the optical spectrum. A possible process would bc the formation of a metallic film at the surface of the sample resulting of a sputtering mechanism. Townsend [3] has shown that . the halogen ions are ejected along $\langle 110\rangle$ directions from the surface of the sample during irradiation and that the remaining layer is evaporated with the normal law of evaporation. However, we first postulated that such a layer was formed during implantation and remained condensed at the surface at low temperature, and then was evaporated when the sample was warmed up to room temperature. Complementary experiments were performed to check this hypothesis.

2. Scanning electron microscope observations. An evaporation of a thin film of gold is performed, before observation, on the surface of the sample, to prevent the effect of the electrical charge of the insulating crystal.

The surface of a sample implanted at room temperature does not present any crater that would be due to the erosion by a sputtering effect. The implanted zone appears with a poor light contrast, by comparison to the non irradiated part of the crystal. The surface of the sample remains flat for the implanted ion doses that we consider in that study $\left(<10^{17}\right.$ ions $\left./ \mathrm{cm}^{2}\right)$ whereas a blistering effect may be observed for heavely implanted crystals
( $>10^{18}$ ions $/ \mathrm{cm}^{2}$ ). The typical aspect of such blisters is presented in photograph 6 .

Photographs 3, 4 and 5 indicate that the crystals, implanted at low temperature and observed at room temperature, have been much more alterated by the implantation process. The photograph 3 , that represent the border region between the irradiated and the non irradiated zone of crystal, shows that entire crystalline planes have been removed from the sample. This effect is more important from outside to the center of the irradiated zone and we can see in photograph 4 that only small crystalline islands remain on the new surface that present a more granular aspect than the smooth initial surface of the crystal. In photograph 5 some details of the border region of photograph 3 may be observed. In particular some pieces of crystalline planes have not been completely taken off. The depth of the damaged zone may be estimated to about 0.5 micron, that corresponds approximately to the penetration depth of $500 \mathrm{keV}$ potassium ions.

It appears then that discoloration effect of low temperature implanted crystals is not due to a perturbation of the primary process of defect creation, by a ionisation induced sputtering mechanism, but is associated to the implantation process in itself. This effect appears for implanted ion doses far lower than the doses required for a blistering effect. It seems also difficult to explain this new phenomenon by the implantation induced mechanical stresses, because it has nether been observed with rare gas ion implantation and seems to be a property of high concentrations of alkali ions at low temperature. We reported in paper [1] the transformation of the infrared absorption into the band associated to the implanted ions and observed during room temperature implantations. However optical absorption only gives a qualitative analysis for inhomogeneous distribution of defects and we performed a Rutherford backscattering analysis, to get the implantation profile and its thermal evolution.

3. Rutherford backscattering measurements. --. The principle of the mcthod is to use an incident monoenergetic beam of light particles as a probe and to look at the energy spectrum of the particles backscattered by the analysed target. For a definite chemical element, the backscattering spectrum gives the in-depth distribution of the element. The surface atoms are observed at high energies and the energy losses of the analysing particles in the target produce a shift toward lower energies of the in-depth elements. It is possible to calculate the distribution of a heavy element in a light matrix from the backscattering spectrum.

Figure 7 gives the distribution of implanted ions obtained at two different points of a LiF crystal implanted at low temperature with $10^{17}$ potassium ions $/ \mathrm{cm}^{2}$. These distributions are deduced from the 


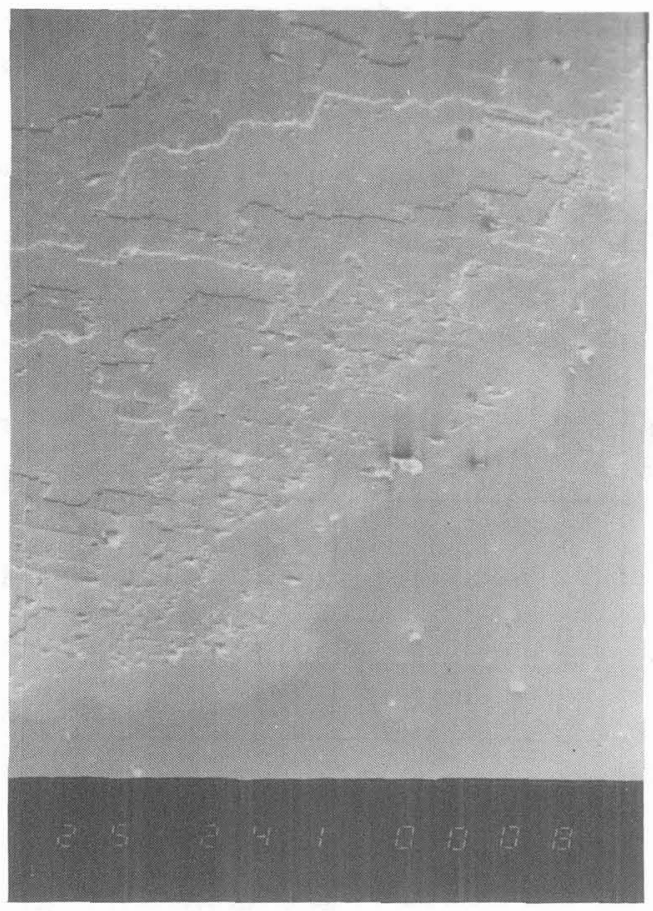

Fig. 3. - SEM photograph of the surface of a LNT implanted crystal (Magnification $0.6 \times 240$ )-ion dose $2 \times 10^{17} \mathrm{~K}^{+}$ ions $/ \mathrm{cm}^{2}$.

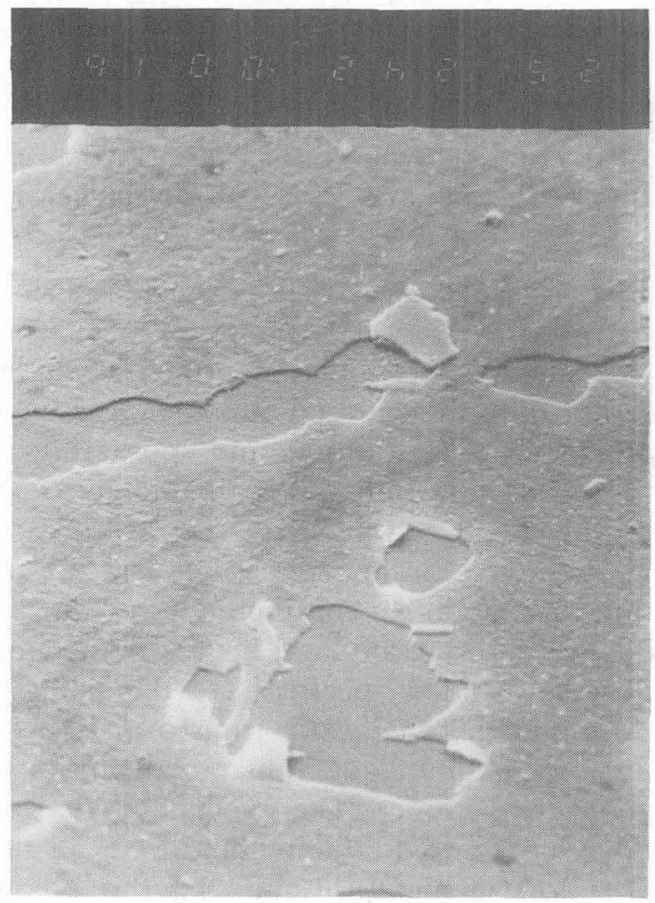

Fig. 5. - Details of the same crystal in the border region between irradiated and non irradiated area (Magnification $0.6 \times 2400$ ).

backscattering spectra, that have been performed at room temperature, as the forthcoming spectra. They show that there is a peak at the surface for the distribution of the implanted ions when the profile is determined at the center, whereas such a peak does

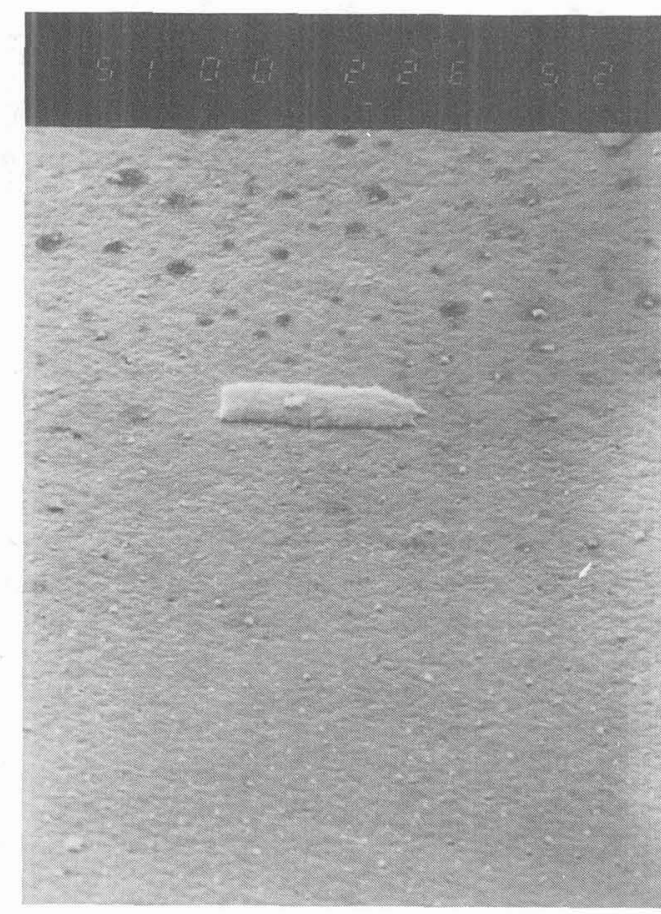

Fig. 4. - Details of the same crystal in the center of the irradiated area (Magnification $0.6 \times 3200$ ).

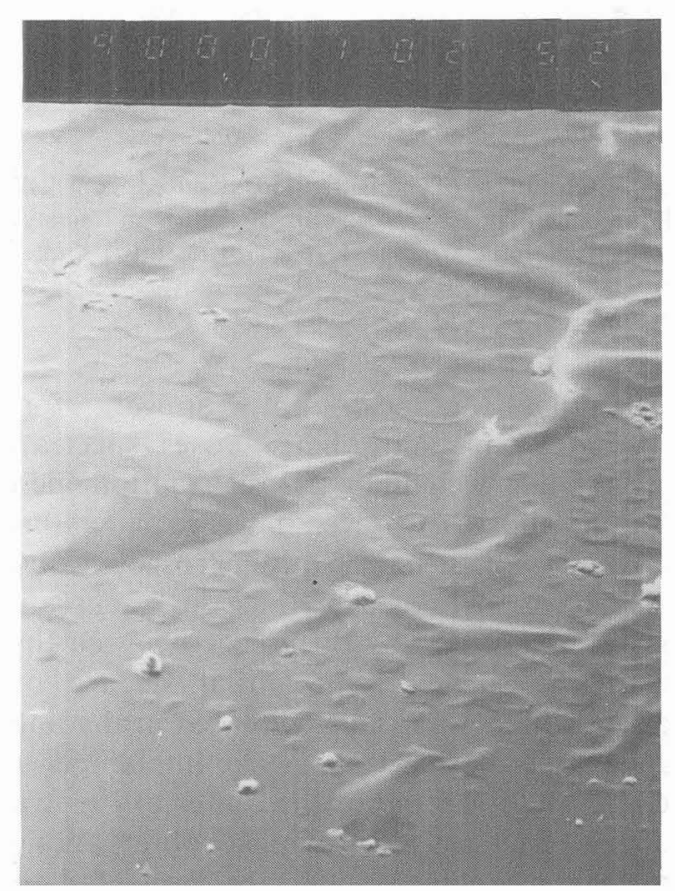

Fig. 6. - SEM photograph of the surface of a RT implanted crystal (Magnification $0.6 \times 200$ ). Ion dose $10^{18} \mathrm{~K}^{+}$ions $/ \mathrm{cm}^{2}$.

not exist in the profile relative to the border of the irradiated zone, where we said that the bleaching effect was not complete. The surface peak is then associated to the discoloration of the sample as it is confirmed by the spectra of figure 8 in which we 

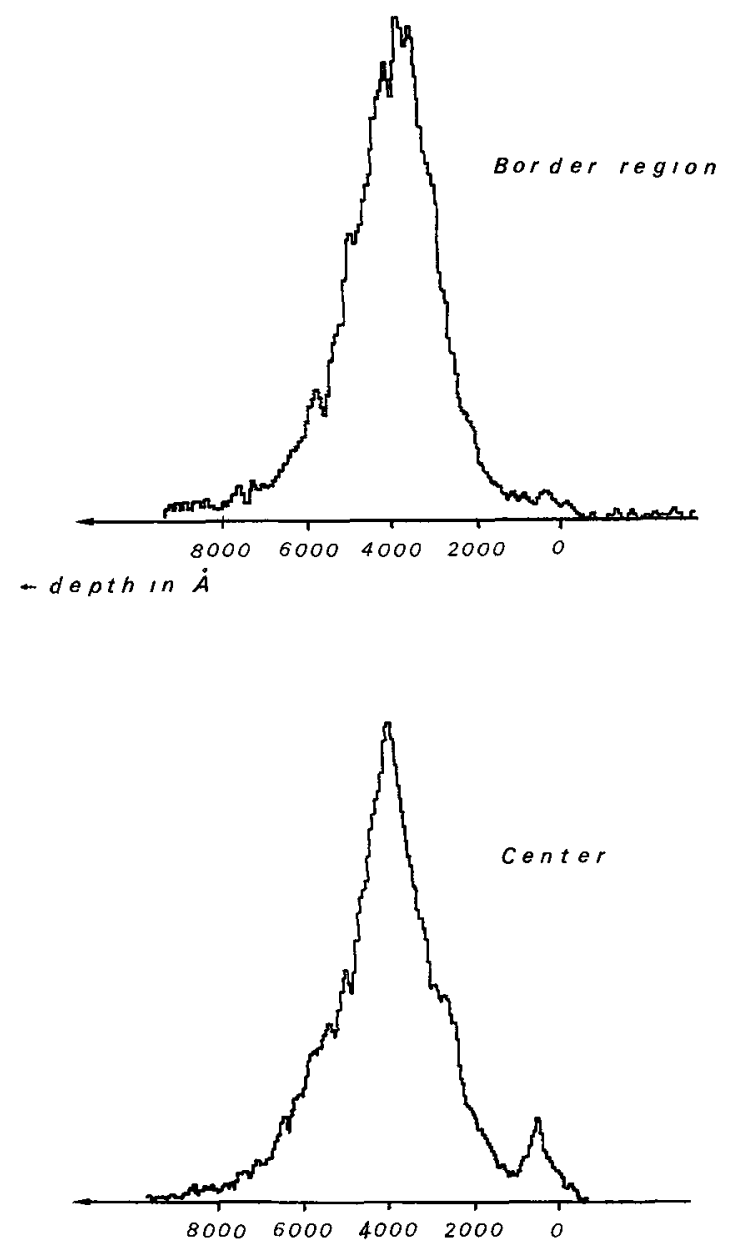

Fig. 7. - Distribution of implanted ions deduced from RBS. LiF crystal implanted at LNT with $10^{17} \mathrm{~K}^{+} / \mathrm{cm}^{2}$ and analysed at $\mathrm{RT}: a)$ center of the irradiated area $; b$ ) near the limit of the irradiated area.

can see that the peak only appears for the $6 \times 10^{16} \mathrm{ions} / \mathrm{cm}^{2}$ and higher doses spectra, and that its relative weight in the distribution increases with the ion dose. However if we consider the previous results of the electron microscopy observation, we have to take care that the backscattering technique cannot do any difference between the two levels of the surface: the initial surface of the crystal and the new surface displaced in the implanted zone, after the reaction of the implanted crystal to the air. The spectrum of the center of the irradiated zone is then only an average observation over microscopical zones, in which the implanted zone is alternatively at the surface or at its normal depth, what gives the explanation of the surface peak. We also observe a peak of oxygen in the backscattering spectra of figure 8 , what may be attributed to the oxidation of the potassium at the surface of the sample. It is also probable that a part of the

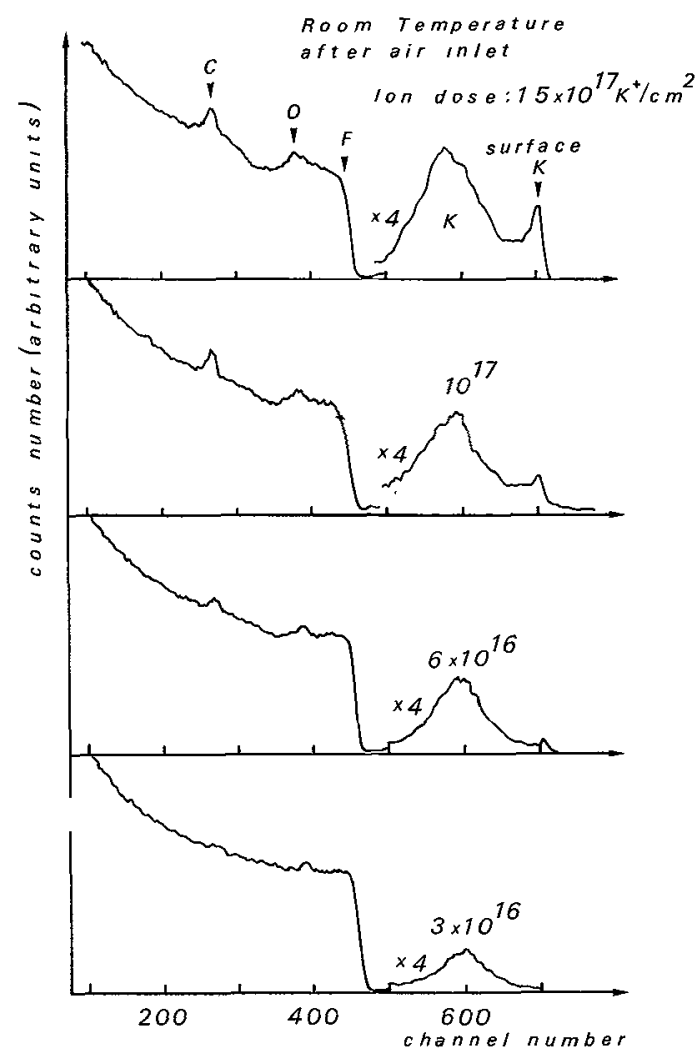

Fig. 8. - RBS spectra of LNT implanted crystals and observed at RT for increasing ion doses.

implanted potassium has been evaporated after the reaction of the implanted zone to the oxygen of the air.

4. Discussion and conclusion. - There is a straigthforward analogy between the properties of alkali ions implanted layers and the properties of alkali metals thin films. Payan and Roux studied the optical properties of sodium and potassium thin layers $[4,5]$. These films are prepared by evaporation of the alkali metal on a substrate in a static ultra vacuum. According to the temperature of the substrate they obtain a continuous thin film at low temperature and a granular film at room temperature. The absorption spectra have the same shape than ours and there is also a transformation of the continuous state into a granular state of the film near room temperature. Then it appears that a new phase may be induced by implantation of alkali ions in $\mathrm{LiF}$ at low temperature and that this phase has the properties of an alkali thin layer. Investigations are actually undertaken to explain in which conditions such a layer is formed and in particular to elucidate the coalescence process, that we have seen to be characterized by a critical concentration of implanted ions. 


\section{DISCUSSION}

Question. - G. P. Pells.

I would like to mention that at Harwell we have irradiated $\alpha-\mathrm{Al}_{2} \mathrm{O}_{3}$ and $\mathrm{MgO}$ single crystals with $3 \mathrm{MeV} \mathrm{H}^{+}, \mathrm{N}^{+}$and $\mathrm{O}^{+}$ions and observe that the surfaces of the crystals exfoliate at fluences of $\sim 10^{17} \mathrm{ion} / \mathrm{cm}^{2}$ at any temperature within the range $77-1000 \mathrm{~K}$.

\section{Reply. - J. Davenas.}

We also performed implantations with rare gas and did not observe the exfoliation process. All implantations have been performed at low energies $(<500 \mathrm{keV})$. In our case the formation of a continuous metallic film is confirmed by conductivity measurements. We observe a variation of conductivity from $10^{-16} \Omega^{-1} \mathrm{~cm}^{-1}$ to $10^{-5} \Omega^{-1} \mathrm{~cm}^{-1}$ during implantation.

\section{References}

[1] Davenas, J., Perez, A. and Dupuy, C., J. Physique Colloq. 37 (1976) C7-531.

[2] Davenas, J., Perez, A., Thevenard, P. and Dupuy, C., Phys. Status Solidi A 19 (1973) 679.
[3] Townsend, P. D., Browning, R., Garlant, D. J., Kelly, J. C., Mahjoobi, A., Michael, A. J. and Saidoh, M., Radiat. Eff. 30 (1976) 55.

[4] Payan, J. C. and Roux, D., Opt. Commun. 7 (1973) 26.

[5] Payan, J. C. and Roux, D., Opt. Commun. 11 (1974) 182. 